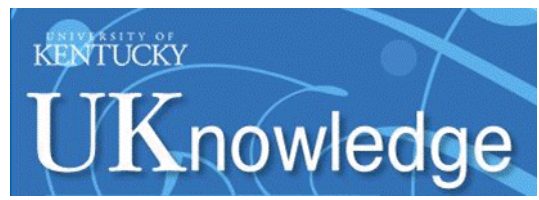

University of Kentucky

UKnowledge

$11-2019$

\title{
Overview of Flywheel Systems for Renewable Energy Storage with a Design Study for High-Speed Axial-Flux Permanent-Magnet
}

\section{Machines}

\author{
Murat G. Kesgin \\ University of Kentucky, murat.kesgin@uky.edu \\ Peng Han \\ University of Kentucky, peng.han@uky.edu \\ Narges Taran \\ University of Kentucky, narges.taran@uky.edu \\ Dan M. Ionel \\ University of Kentucky, dan.ionel@uky.edu
}

Follow this and additional works at: https://uknowledge.uky.edu/peik_facpub

Part of the Power and Energy Commons

Right click to open a feedback form in a new tab to let us know how this document benefits you.

\section{Repository Citation}

Kesgin, Murat G.; Han, Peng; Taran, Narges; and Ionel, Dan M., "Overview of Flywheel Systems for Renewable Energy Storage with a Design Study for High-Speed Axial-Flux Permanent-Magnet Machines" (2019). Power and Energy Institute of Kentucky Faculty Publications. 10.

https://uknowledge.uky.edu/peik_facpub/10

This Conference Proceeding is brought to you for free and open access by the Power and Energy Institute of Kentucky at UKnowledge. It has been accepted for inclusion in Power and Energy Institute of Kentucky Faculty Publications by an authorized administrator of UKnowledge. For more information, please contact UKnowledge@lsv.uky.edu. 


\title{
Overview of Flywheel Systems for Renewable Energy Storage with a Design Study for High-Speed Axial-Flux Permanent-Magnet Machines
}

\author{
Digital Object Identifier (DOI) \\ https://doi.org/10.1109/ICRERA47325.2019.8996526 \\ Notes/Citation Information \\ Published in 2019 8th International Conference on Renewable Energy Research and Applications \\ (ICRERA).
}

(C) 2019 IEEE Copyright Notice. "Personal use of this material is permitted. Permission from IEEE must be obtained for all other uses, in any current or future media, including reprinting/republishing this material for advertising or promotional purposes, creating new collective works, for resale or redistribution to servers or lists, or reuse of any copyrighted component of this work in other works."

The document available for download is the authors' manuscript version that is accepted for publication. The final published version is copyrighted by IEEE and available as: M. G. Kesgin, P. Han, N. Taran, and D. M. Ionel, "Overview of Flywheel Systems for Renewable Energy Storage with a Design Study for Highspeed Axial-flux Permanent-magnet Machines," 8th International Conference on Renewable Energy Research and Applications (ICRERA), Brasov, Romania, Nov. 3-6, 2019, pp. 1026-1031, doi: 10.1109/ ICRERA47325.2019.89965 


\title{
Overview of Flywheel Systems for Renewable Energy Storage with a Design Study for High-speed Axial-flux Permanent-magnet Machines
}

\author{
Murat G. Kesgin, Student Member, IEEE, Peng Han, Member, IEEE, Narges Taran, Student Member, IEEE, \\ and Dan M. Ionel, Fellow, IEEE
}

SPARK Laboratory, Department of Electrical and Computer Engineering,

University of Kentucky, Lexington, KY, USA

murat.kesgin@uky.edu, peng.han@uky.edu,narges.taran@uky.edu, dan.ionel@ieee.org

\begin{abstract}
Flywheel energy storage is considered in this paper for grid integration of renewable energy sources due to its inherent advantages of fast response, long cycle life and flexibility in providing ancillary services to the grid, such as frequency regulation, voltage support, etc. The fundamentals of the technology and recent developments are reviewed, firstly with an emphasis on the design considerations and performance metrics. Then the progress and development trends in electric motor/generators employed in flywheel energy storage systems (FESS) are summarized, showing the potential of axial-flux permanent-magnet (AFPM) machines in such applications. Design examples of high-speed AFPM machines are provided and evaluated in terms of specific power, efficiency, and open-circuit losses in order to validate their suitability in FESS.
\end{abstract}

Index Terms-Axial-flux, flywheel energy storage system, motor/generator, permanent-magnet.

\section{INTRODUCTION}

Recent technological developments have spawned the growth of renewable energy resources, such as solar and wind power. The intermittent nature of these resources may introduce issues with system stability, reliability and power quality. Storing power from these intermittent sources with energy storage systems partially decouples the energy generation from demand and is thus considered as an effective approach to addressing problems introduced by the penetration of renewable energies [1], [2]. Interests in energy storage have seen rapid growth recently and the renewable energy industry is expected to generate a larger proportion of the overall energy consumption in the near future.

Energy can be stored through various forms, such as ultracapacitors, electrochemical batteries, kinetic flywheels, hydroelectric power or compressed air. Their comparison in terms of specific power, specific energy, cycle life, self-discharge rate and efficiency can be found, for example, in [3]. Compared with other energy storage methods, notably chemical batteries, the flywheel energy storage has much higher power density but lower energy density, longer life cycles and comparable efficiency, which is mostly attractive for short-term energy storage.
Flywheel energy storage systems (FESS) have been used in uninterrupted power supply (UPS) [4]-[6], brake energy recovery for racing cars [7], public transportation [8], offhighway vehicles [9], container cranes/straddle carriers [10], and grids [11]-[13]. They were also proposed to be used in the pulse power supply for electromagnetic launch systems [14]. Major manufacturers of FESS are tabulated in Table I, focusing on UPS, brake energy recovery and grid applications.

The FESS technology has been reviewed from various perspectives, such as the system level [18]-[21], mechanical aspects [22] and specific applications [23]. The latest technology progress focused on reducing the self-discharge and performing ancillary services, such as frequency regulation, voltage support, renewable energy integration and potential peak electric power shaving, showing the possibility of introducing FESS in grid applications [24].

\section{Fundamentals OF FESS}

\section{A. Configurations and Principle of Operation}

A typical FESS, as shown in Fig. 1, includes a flywheel rotor, an electric motor/generator and its associated drive, bearing systems, and a containment. The flywheel rotor is a moving mass that stores the kinetic energy. The machine and drive work in three modes of operation, i.e., charging, standby and discharging, and perform the energy conversion, as illustrated in Fig. 2. During the charging mode, the machine works as a motor and accelerates the flywheel, while in discharging mode, the machine serves as a generator and extracts the stored energy to supply the load.

Bearings are used to keep the flywheel rotor in place with very low friction. They can be mechanical, magnetic or hybrid. Active and/or passive magnetic bearings are usually employed to hold the flywheel during operation, ensuring a long life, reduced losses and low maintenance [25]. The high-temperature superconducting (HTS) type has also been proposed to levitate and rotate the flywheel [26]. Mechanical types may also be included to hold the flywheel while it is stationary or below operational speed. Additional catch bearings may be installed to 
Table I

MAJOR MANUFACTURERS OF FESS AND THEIR APPLICATIONS

\begin{tabular}{l|c|c}
\hline Manufacturer & Ratings & Applications \\
\hline ABB & $1,800-3,600 \mathrm{rpm}, 100-1,500 \mathrm{~kW}$ & Renewable microgrid stabilization [11] \\
Active Power & Max. 10,000 rpm, 225 kW & UPS [4] \\
Beacon Power, LLC & Max. 16,000 rpm, 100 kW & Utility grid [13] \\
Calnetix Technologies, LLC & $25,000-35,000 \mathrm{rpm}, 125 \mathrm{~kW}$ & UPS \\
Williams Hybrid Power & Max. 36,000-45,000 rpm, 150-180 kW & Brake energy recovery for vehicles [7] \\
Kinetic Traction Systems & Max. 36,000 rpm, 250-400 kVA & Brake energy recovery, UPS and grid [15] \\
PowerThru & - & UPS [6] \\
PUNCH Flybrid & Max. 60,000 rpm, 60 kW & Brake energy recovery for vehicles [9] \\
Ricardo PLC & Max. 44,000 rpm, 100 kW & Brake energy recovery for vehicles [16] \\
Temporal Power & - & Utility grid [17] \\
\hline
\end{tabular}

provide a fail-safe system. The containment not only provides an environment with low aerodynamic drag, but also shields the fragments in the event of rotor failures.

\section{B. Sizing Procedure for Flywheel Rotors}

Flywheel rotors are built as solid or hollow cylinders. The maximum kinetic energy stored in the flywheel $E_{k}$ is:

$$
E_{k}=\frac{1}{2} J \omega^{2},
$$

where $\omega_{\max }$ is the maximum angular velocity, $J$ is the moment of inertia, which is a function of the mass and shape of the rotor, and for hollow cylinders, it can be expressed as:

$$
J=\frac{1}{2} m\left(r_{o}^{2}+r_{i}{ }^{2}\right)=\frac{\rho \pi h}{2}\left(r_{o}^{4}-r_{i}^{4}\right),
$$

where $m$ is the flywheel rotor mass and $\rho$ the mass density, $r_{o}$ and $r_{i}$ are the outer radius and inner radius of a hollow cylinder flywheel, respectively, $h$ is the thickness of the flywheel rotor in axial direction. The useful energy of a flywheel within a speed range of minimum speed $\omega_{\min }$ and maximum speed $\omega_{\max }$ can be obtained by:

$$
E_{k e f f}=\frac{1}{2} J\left(\omega_{\max }^{2}-\omega_{\min }^{2}\right)=\frac{1}{2} J \omega_{\max }^{2}\left(1-\frac{\omega_{\min }^{2}}{\omega_{\max }^{2}}\right),
$$

The ratio $\omega_{\min } / \omega_{\max }$ depends on the voltage variation and maximum torque for a given power rating. The peak torque occurs at the lowest speed in discharging mode, as shown in Fig. 2. A typical value for $\omega_{\min } / \omega_{\max }$ is 0.5 , in which case, $75 \%$ of the total stored energy can be extracted from the flywheel. The selection of this value also has an impact on the life cycle [27].

The outer radius is limited by the yield stress of the material $\sigma_{y}$, external stress $\sigma_{s h}$ introduced by the shrink-fit between the flywheel rotor and shaft, Poisson's ratio $v$ and the maximum rotating speed of the flywheel $\omega_{\max }$ :

$$
r_{o}<\sqrt{\frac{4\left(\sigma_{y}-\sigma_{s h}\right)}{(3+v) \rho \omega_{\max }^{2}}-\frac{1-v}{3+v} r_{i}^{2}},
$$

The thickness in the axial direction can then be estimated by:

$$
h=\frac{4 E_{k}}{\rho \pi \omega_{\max }^{2}\left(r_{o}^{4}-r_{i}^{4}\right)} .
$$

Based on (4) and (5), the maximum specific energy is:

$$
\frac{E_{k}}{m}=K \frac{\sigma_{y}}{\rho},
$$

where $K$ is the shape factor of the hollow cylinder flywheel with isotropic material, such as steel:

$$
K=\frac{\left(1-\frac{\sigma_{s h}}{\sigma_{y}}\right)\left[\left(\frac{r_{i}}{r_{o}}\right)^{2}+1\right]}{\left[(1-v)\left(\frac{r_{i}}{r_{o}}\right)^{2}+(3+v)\right]} .
$$

The shape factor $K$ is a measurement of material utilization and depends on the flywheel geometry, as summarized in [28]. Considering ease of manufacturing and assembling, conventional flywheel rotors are hollow cylinders with central holes to install the shaft, which are used to couple the electric motor/generator.

Equation (6) indicates that the specific energy (energy per mass unit) and energy density (energy per volume unit) of the flywheel are dependent on its shape, expressed by the shape factor $K$, and the yield stress $\sigma_{y}$. By contrast, the power rating depends on the motor/generator characteristics. This means the energy and power rating can be sized independently, depending on the application requirements. This flexibility is a particularly advantageous feature of flywheel technology.

To achieve high-specific-energy flywheels, strong materials with low mass densities are needed. Typical materials used in flywheel rotors are listed in Table II based on data from [28]. The fatigue strength for a cycle life of $10^{7}$ cycles $\sigma_{f}$ instead of the yield strength is used to give more practical estimations about the energy density and specific energy. The calculation of $E_{k} / m$ and $E_{k} / V$ for hollow cylindrical flywheels made of metal uses $K=0.305$ and $K=0.500$ is used for flywheels made of filamentary composites.

\section{Performance Metrics}

Uniform parameters and evaluation methods have been defined by the Pacific Northwest National Laboratory (PNNL) and Sandia national Laboratories (SNL) to serve as the basis to compare the performance of different energy storage systems. The definitions are applicable to various energy storage methods but not all of them are of special interest to a specific storage method. In this section, only metrics essential to FESS 


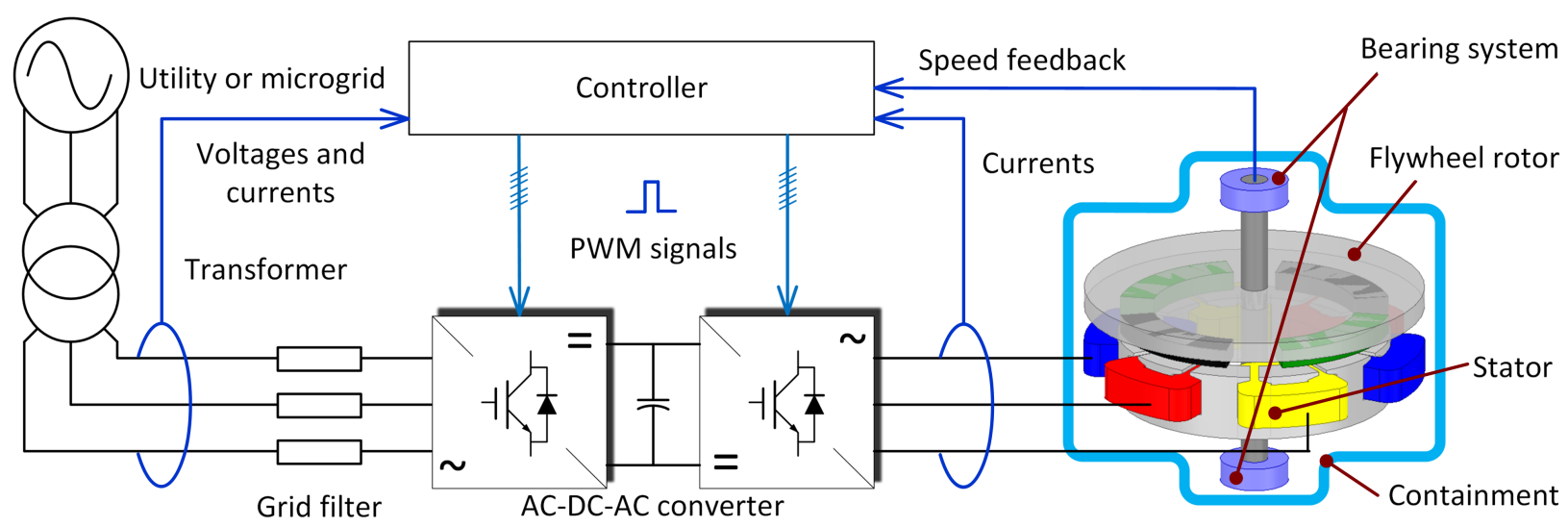

Figure 1. A typical FESS with a solid flywheel rotor. A transparent view of the rotor back iron is employed in order to show PMs and stator coils.

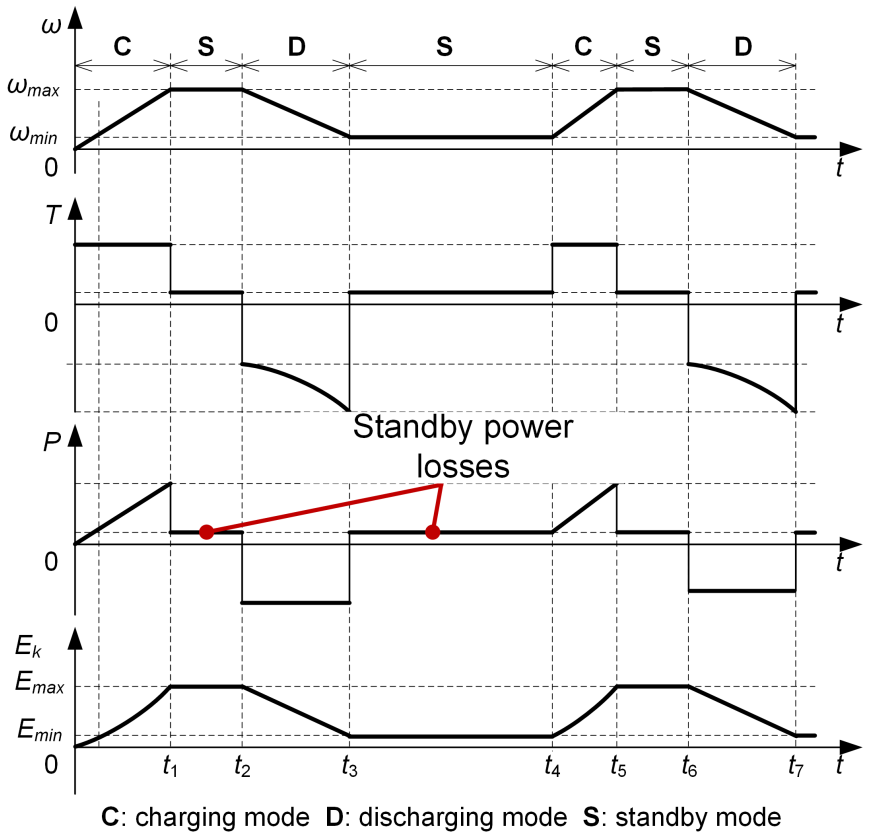

Figure 2. Typical operating cycles for FESS. The power rating is limited by the lowest speed in discharging mode, where the maximum torque occurs. The standby power losses are shown disproportionately for illustration purposes.

Table II

FLYWHEEL MATERIAL CHARACTERISTICS

\begin{tabular}{l|c|c|c|c|c}
\hline Material & $\begin{array}{c}\rho \\
\left(\mathrm{kg} / \mathrm{m}^{3}\right)\end{array}$ & $\begin{array}{c}\sigma_{y} \\
(\mathrm{MPa})\end{array}$ & $\begin{array}{c}\sigma_{f} \\
(\mathrm{MPa})\end{array}$ & $\begin{array}{c}E_{k} / V \\
\left(\mathrm{kWh} / \mathrm{m}^{3}\right)\end{array}$ & $\begin{array}{c}E_{k} / m \\
(\mathrm{Wh} / \mathrm{kg})\end{array}$ \\
\hline Steel - wrought & 7,800 & 950 & 550 & 46.6 & 6.0 \\
Steel - maraging & 8,000 & 2,337 & 765 & 64.8 & 8.1 \\
Titanium & 4,500 & 1,186 & 662 & 56.1 & 12.4 \\
Fiber - glass & 2,000 & 1,100 & 220 & 30.0 & 15.0 \\
Fiber - aramid & 1,400 & 1,400 & 700 & 97.0 & 69.0 \\
Fiber - Carbon & 1,550 & 2,000 & 1,600 & 222.0 & 143.0 \\
\hline
\end{tabular}

are presented. Table III lists the statistical results of published FESS in terms of these performance. The definitions of depth of discharge, round-trip efficiency and standby power losses are presented below. The details related to other performance metrics can be found in [29].

The depth of discharge is the percentage of flywheel energy capacity that has been discharged, expressed as a percentage of
Table III

Published MEtrics of FESS. Statistical RESUlts From MULTIPLE SOURCES.

\begin{tabular}{l|c}
\hline Metric & Value \\
\hline Power rating (MW) & $0.001-10$ \\
Specific energy $(\mathrm{Wh} / \mathrm{kg})$ & $5-200$ \\
Specific power $(\mathrm{W} / \mathrm{kg})$ & $400-30,000$ \\
Energy density $\left(\mathrm{kWh} / \mathrm{m}^{3}\right)$ & $0.25-424$ \\
Power density $\left(\mathrm{kW} / \mathrm{m}^{3}\right)$ & $40-2,000$ \\
Round-trip efficiency $(\%)$ & $70-96$ \\
Calendar life (year) & $15-20$ \\
Cycle life (cycles) & $10,000-100,000$ \\
Self-discharge rate $(\% /$ day) & $24-100$ \\
\hline
\end{tabular}

the maximum capacity. The depth of discharge of flywheels is up to the output power and the maximum current of the power converter.

The round-trip efficiency is expressed as a percentage of the useful output energy with respect to the input energy over one duty cycle under normal conditions. The time period from $t_{3}$ to $t_{7}$ in Fig. 2 is a typical operating cycle. Round-trip efficiency is a pivotal design factor especially for long-term FESS. Nowadays, the round-trip efficiency of FESS can reach $80 \%-95 \%$. The key metrics of FESS listed in Table III are based on data compiled from [4]-[7], [9], [11], [13], [15]-[18].

The standby power losses are loss components that gradually reduce the stored energy in the standby mode of operation. The standby power losses depend on the design of flywheels and are usually caused by friction, aerodynamic drag and open-circuit motor/generator losses that slow down the rotor. To reduce the standby power losses, vacuum containment and magnetic bearings are usually employed [20], [21]. The standby losses are designed to be very low, typically less than $25 \mathrm{~W} / \mathrm{kWh}$ of the stored energy and in the range of $1-2 \%$ of the rated output power.

\section{ELECTRIC MACHINES FOR FESS}

\section{A. Machine Topologies}

PM brushless machines and squirrel-cage induction machines of the radial-flux type have been widely used in FESS. Radialflux and transverse-flux homopolar induction machines have drawn much attention during the past two decades considering 
their low-standby-loss nature and the ease of integrating the electric machine rotor with the flywheel [30]-[32]. However, the torque/power density of this type is relatively low compared with induction machines and PM brushless machines [33]. Other machines, such as synchronous reluctance machines, and bearingless versions of PM brushless machines and induction machines have also been proposed, yet experimental demonstrations of the feasibility are still rare.

\section{B. Research and Development Trends}

The research in electric machines for FESS mainly focuses on the reduction of standby power losses. The use of magnetic or HTS bearings and installing the flywheel in low-pressure containments are effective ways to achieve the goal. Flywheel energy storage tends to use various active/passive magnetic and HTS bearings to reduce the losses caused by friction as well as extend the lifetime for maintenance-free operation. Retractable configurations, i.e., adjustable airgaps [34], [35], and slotless or coreless structures [36] have also been used to reduce the standby power losses. The heat dissipation and thermal analysis of electric machines are of significance if the motor/generators are included in the low-pressure containments considering the very low convective heat transfer in such conditions.

\section{AFPM Machines}

AFPM brushless machines have also been proposed for FESS. An AFPM machine in a vertical arrangement with two stators and one central rotor has been presented to improve the round-trip efficiency by making full use of the axial forces instead of active/passive bearings in [37]. The central rotor serves as the flywheel of the integrated system and the magnetic attractions between the rotor and stators were controlled appropriately to counteract the rotor gravity. A flywheel system with an axial-flux motor/generator whose airgap can be adjusted dynamically to reduce the standby power losses during idle periods has also been proposed [35]. A micro-flywheel energy storage with an AFPM machine and HTS bearing was fabricated and tested in [38]. The disk-type aluminum rotor with high moment of inertia was used as the flywheel rotor and the maximum speed reached 51,000 rpm.

\section{Design Study of High-SPEed AFPM Machines FOR FESS}

In this section, two main topologies, i.e., the conventional single-sided AFPM machine with stator and rotor cores and the coreless structure with two rotors and a central stator, as illustrated in Fig. 3, are evaluated by finite element analysis (FEA) to show their suitability for FESS applications in terms of specific power, efficiency and open-circuit losses. Both 3phase and 2-phase windings can be employed in the AFPM machines under study. The coreless design example adopts the 2-phase wave winding in order to show the enhanced faulttolerant capability due to the magnetic decoupling between the two phases.

The proposed motor/generator designs are modular lowpower high-speed units. They have the same power rating

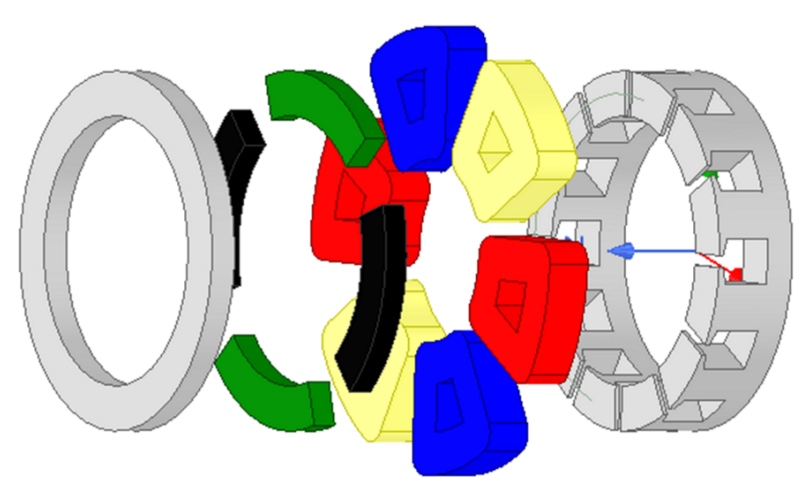

(a)

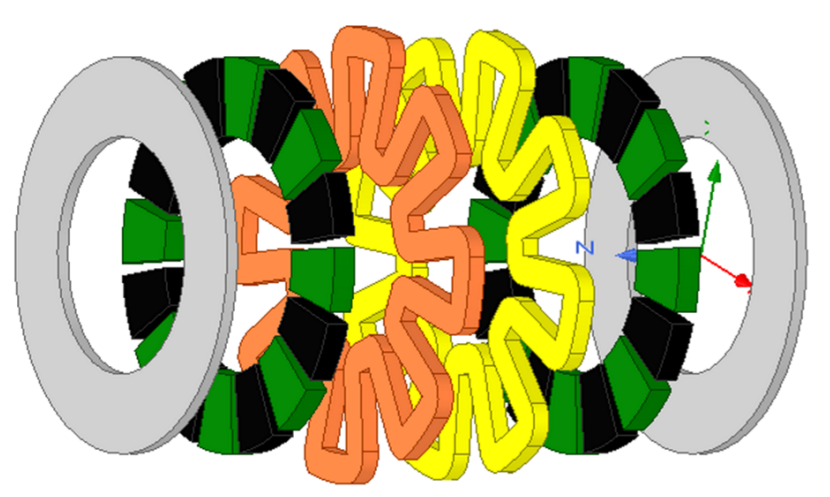

(b)

Figure 3. Two typical AFPM machine topologies, (a) with stator core, (b) without stator core. Concentrated or wave-type windings may be used to reduce the length of end winding and associated copper losses, as well as for the ease of manufacturing. Solid conductors are depicted for illustration, and they would be made of fine wire or Litz wire to minimize the high-frequency AC losses.

$17.5 \mathrm{hp}$ and will run between 25,000 rpm and 50,000 rpm, corresponding to a maximum depth of discharge 0.5 . The same envelope dimensions, i.e., total outer diameter $=200 \mathrm{~mm}$ and total axial length $=50 \mathrm{~mm}$, are used for both the designs with and without stator core. The magnet grade is NdFeB N30 and the stator core is made of lamination steel M15-29G.

For the AFPM machine with core, the fundamental frequency at very high speed operation and number of poles are limited by the core losses, which are approximately proportional to the square of fundamental frequency. By eliminating the stator core and associated core losses, the coreless design may employ a higher number of poles. A parametric study is carried out to show the influence of number of poles on the motor/generator performance. The current density is adjusted accordingly to achieve the target torque $5 \mathrm{Nm}$ at $25,000 \mathrm{rpm}$. The motor/generator can operate up to $50,000 \mathrm{rpm}$ but the torque is reduced to $2.5 \mathrm{Nm}$ to maintain constant output power.

As shown in Fig. 4, the coreless machine designs can achieve a specific power output of around $6 \mathrm{~kW} / \mathrm{kg}$, regardless of the number of poles from 4 to 10 , while the design with stator core has a much lower value due to the required large core volume and mass. Furthermore, the applied current density reduces with the increase in the number of poles for coreless machines. This is caused by the relatively low torque capability of machines 


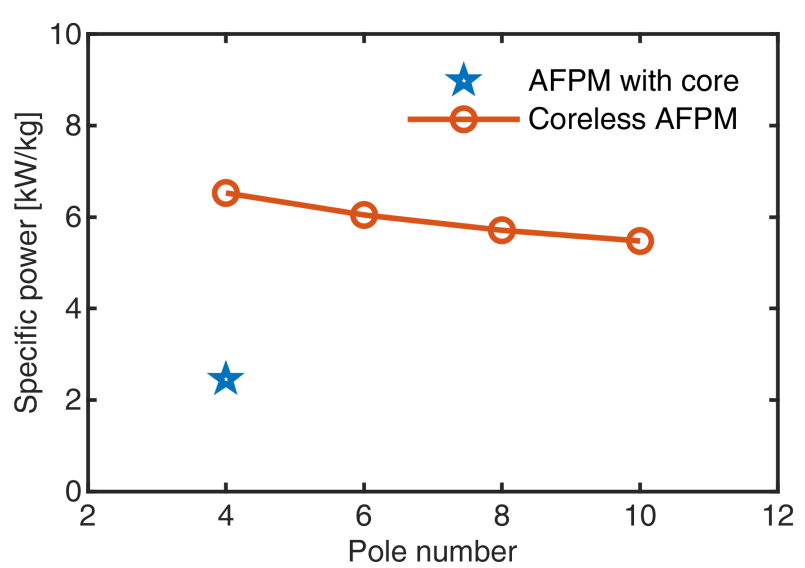

Figure 4. Specific power of AFPM machine design examples with and without stator core. The pole number of the design with stator core is mainly limited by the core losses at high rated frequencies. In contrast, the coreless design may have more poles due to the elimination of core losses.

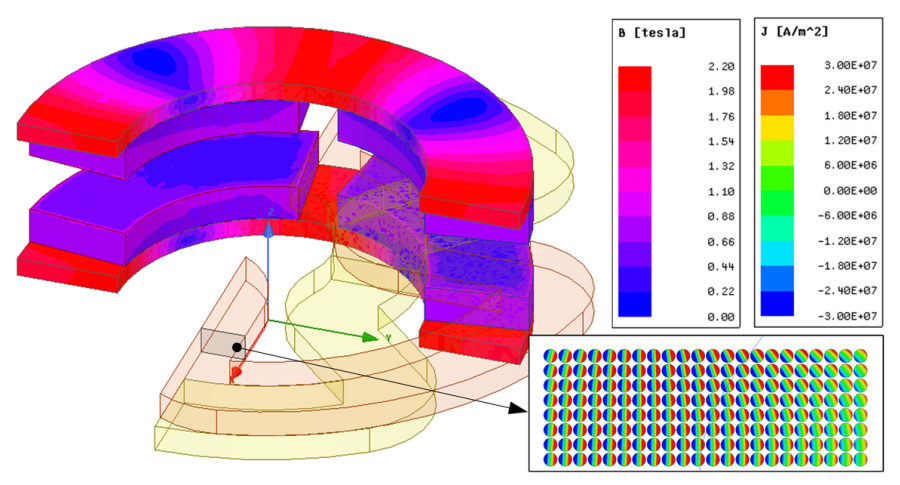

Figure 5. Flux density and instantaneous current density distribution for an example 4-pole coreless design using multi-strand conductors at 25,000 rpm. The high induced current densities indicate that Litz wire may need to be used to mitigate the high frequency conductor losses.

with a low number of poles for a small ratio of total axial length to total diameter [39].

It may be noted that coreless machines tend to feature high conductor AC losses, due to eddy currents induced by the timedependent variations of the airgap magnetic field, and therefore would need to be designed with fine multi-strand conductors or Litz wire. For the example design based on multi-strand conductors shown in Fig. 5, the induced instantaneous current density is more than twice the applied current density at 25,000 rpm, indicating that the use of Litz wire may be necessary in this case.

The efficiency of the designed electric machines in charging/discharging mode is shown in Fig. 6. It may be observed that the efficiency is almost invariant with the number of poles for the operation at $25,000 \mathrm{rpm}$, while at $50,000 \mathrm{rpm}$, the efficiency drops sharply with the increase of pole number, indicating that either a lower rotor polarity, or a winding design with Litz wire may be the right choice.

It is worth noting that in order to operate AFPM machines with relatively large pole numbers at very high speeds, it is

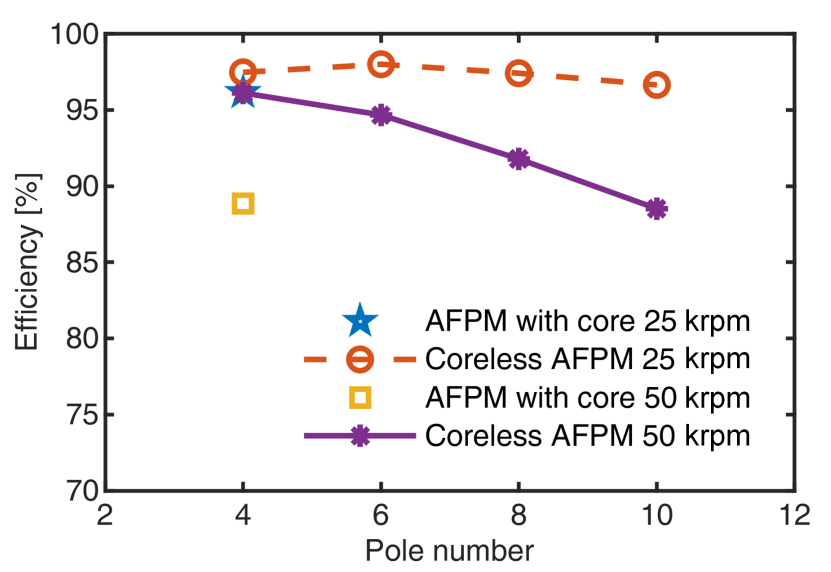

Figure 6. Efficiency of AFPM machine design examples with and without stator core at 25,000 rpm and 50,000 rpm.

necessary to use wide-bandgap (WBG) switching devices to enable higher fundamental frequency as well as improve the system efficiency, such as sillicon carbide ( $\mathrm{SiC})$ and gallium nitride $(\mathrm{GaN})$ metal oxide semiconductor field effect transistors (MOSFETs). Inverters with all WBG devices or hybrid switch converters can be employed to drive the proposed low-power high-speed units.

FEA results indicate that designs with a low number of poles are preferred in terms of open-circuit loss. In order to take advantage of the high torque per ampere provided by higher polarity designs, the open circuit loss can be mitigated by increasing the airgap length in standby mode.

The round-trip efficiency is closely related to both the efficiency in charging/discharging mode and power losses in standby mode. In short-term energy storage applications, the efficiency in charging/discharging mode may be more important. For long-term flywheel energy storage, the standby mode may last a long period of time and the standby power losses become the dominating loss component in a whole round trip.

Based on the calculation results of the design examples, it can been found that AFPM machines, especially those with stator cores, are subject to the constraints on the fundamental frequency. Low number of poles are favored to reduce the open-circuit loss. In the case of coreless machines, relatively larger pole numbers provide higher specific power at the same current density level and higher efficiency in the designed charging/discharging speed range. Coreless designs may need to use Litz wire in order to minimize the additional conductor losses at high frequency. It should be noted that the current density in conductors and heat dissipation of stator windings may bring about additional challenges in designing high-speed AFPM machines for FESS applications.

\section{CONCLUSION}

This paper reviews the fundamentals and recent developments of flywheel energy storage technology, with an emphasis on applications in microgrid and utility grid for renewable energy integration. To achieve high energy density/specific 
energy, composite materials with high tensile strength and low mass density are becoming increasing popular in constructing flywheel rotors, enabling higher rotor speeds and larger rotor diameters.

High-speed AFPM machines are evaluated in terms of power density/specific power, efficiency, and open-circuit power losses at high rotating speeds, showing their feasibility in FESS with high energy density/specific energy. The adjustable airgap length of AFPM machines may further benefit the selfdischarge reduction in the standby mode. In addition, there is a higher potential to integrate the rotor of axial-flux PM motor/generator with the flywheel rotor due to its disk-like shape. The design study conducted in this paper opens up an opportunity for AFPM machines in the grid integration of renewable energy sources.

\section{ACKNOWLEDGMENT}

The support of National Science Foundation NSF Grant \#1809876, of University of Kentucky, the L. Stanley Pigman endowment and of ANSYS Inc. is gratefully acknowledged.

\section{REFERENCES}

[1] V. A. Boicea, "Energy storage technologies: The past and the present," Proceedings of the IEEE, vol. 102, no. 11, pp. 1777-1794, Nov 2014

[2] S. Vazquez, S. M. Lukic, E. Galvan, L. G. Franquelo, and J. M. Carrasco, "Energy storage systems for transport and grid applications," IEEE Transactions on Industrial Electronics, vol. 57, no. 12, pp. 3881-3895, Dec 2010.

[3] F. Blaabjerg and D. M. Ionel, Renewable Energy Devices and Systems with Simulations in MATLAB®and ANSYS®. CRC Press, May 2017.

[4] ActivePower. [Online]. Available: http://www.activepower.com/enGB/downloads

[5] Calnetix Technologies, LLC. [Online]. Available: https://www.calnetix.com/powerflux-active-magnetic-bearings

[6] PowerThru. [Online]. Available: http://www.power-thru.com/

[7] J. G. R. Hansen and D. U. O'Kain, "An assessment of flywheel high power energy storage technology for hybrid vehicles," Tech. Rep., Dec. 2011, ORNL/TM-2010/280.

[8] M. Andriollo, F. Graziottin, and A. Tortella, "Contact-less electromagnetic recharging system for heavy-duty bus flywheel storage," in 2015 International Conference on Renewable Energy Research and Applications (ICRERA), Nov 2015, pp. 232-237.

[9] PUNCH Flybrid. [Online]. Available: https://punchflybrid.com/applications/

[10] M. M. Flynn, P. McMullen, and O. Solis, "High-speed flywheel and motor drive operation for energy recovery in a mobile gantry crane," in APEC 07 - Twenty-Second Annual IEEE Applied Power Electronics Conference and Exposition, Feb 2007, pp. 1151-1157.

[11] ABB, "Powerstore - renewable microgrid stabilization," Nov. 2017.

[12] S. Sanders, M. Senesky, M. He, and E. Chiao, "Low-cost flywheel energy storage demonstration,” Tech. Rep., 2015. Publication number: CEC-5002015-089.

[13] Beacon Power, LLC. [Online]. Available: https://beaconpower.com/

[14] M. R. Doyle, D. J. Samuel, T. Conway, and R. R. Klimowski, "Electromagnetic aircraft launch system-EMALS," IEEE Transactions on Magnetics, vol. 31, no. 1, pp. 528-533, Jan 1995.

[15] Kinetic Traction Systems, Inc. [Online]. Available: https://kinetictraction.com/flywheel-energy-storage-applications/

[16] Ricardo PLC. [Online]. Available: https://ricardo.com/news-andmedia/news-and-press/flybus-to-start-testing-first-flywheel-hybrid-bus

[17] Temporal power. [Online]. Available: http://temporalpower.ca/

[18] S. Sabihuddin, A. Kiprakis, and M. Mueller, "A numerical and graphical review of energy storage technologies," Energies, vol. 8, no. 1, pp. 172 216, Dec 2014.

[19] M. E. Amiryar and K. R. Pullen, "A review of flywheel energy storage system technologies and their applications," Applied Sciences, vol. 7 , no. 3, pp. 1-21, Mar. 2017.
[20] P. Yulong, A. Cavagnino, S. Vaschetto, Chai Feng, and A. Tenconi, "Flywheel energy storage systems for power systems application," in 2017 6th International Conference on Clean Electrical Power (ICCEP), June 2017, pp. 492-501.

[21] S. Mousavi G, F. Faraji, A. Majazi, and K. Al-Haddad, "A comprehensive review of flywheel energy storage system technology," Renewable and Sustainable Energy Reviews, vol. 67, pp. 477 - 490, 2017.

[22] E. Dragoni, "Mechanical design of flywheels for energy storage: A review with state-of-the-art developments," Proceedings of the Institution of Mechanical Engineers, Part L: Journal of Materials: Design and Applications, vol. 233, no. 5, pp. 995-1004, 2019.

[23] M. Hedlund, J. Lundin, J. De Santiago, J. Abrahamsson, and H. Bernhoff, "Flywheel energy storage for automotive applications," Energies, vol. 8, no. 10 , pp. $10636-10663,2015$.

[24] F. Goris and E. L. Severson, "A review of flywheel energy storage systems for grid application," in IECON 2018 - 44th Annual Conference of the IEEE Industrial Electronics Society, Oct 2018, pp. 1633-1639.

[25] J. Itoh, T. Masuda, D. Sato, T. Nagano, T. Suzuki, and N. Yamada, "Development of magnetic assist system in flywheel energy storage system for power load-leveling," in 2016 IEEE International Conference on Renewable Energy Research and Applications (ICRERA), Nov 2016, pp. 198-203.

[26] M. Strasik, J. R. Hull, J. A. Mittleider, J. F. Gonder, P. E. Johnson, and K. E. McCrary, et al., "An overview of boeing flywheel energy storage systems with high-temperature superconducting bearings," Superconductor Science and Technology, vol. 23, no. 3, p. 034021, Feb 2010.

[27] X. Li, B. Anvari, A. Palazzolo, Z. Wang, and H. Toliyat, "A utility-scale flywheel energy storage system with a shaftless, hubless, high-strength steel rotor," IEEE Transactions on Industrial Electronics, vol. 65, no. 8, pp. 6667-6675, Aug 2018.

[28] F. Thoolen, "Development of an advanced high speed flywheel energy storage system," Ph.D. dissertation, Technische Universiteit Eindhoven, Eindhoven, January 1993.

[29] D. R. Conover, S. R. Ferreira, A. J. Crawford, D. A. Schoenwald, J. Fuller, and D. M. R. S. N. Gourisetti, et al., "Protocol for uniformly measuring and expressing the performance," Tech. Rep., Apr. 2016. PNNL-22010 Rev 2 / SAND2016-3078 R.

[30] P. Tsao, M. Senesky, and S. R. Sanders, "An integrated flywheel energy storage system with homopolar inductor motor/generator and highfrequency drive," IEEE Transactions on Industry Applications, vol. 39, no. 6, pp. 1710-1725, Nov 2003.

[31] E. Severson, R. Nilssen, T. Undeland, and N. Mohan, "Magnetic equivalent circuit modeling of the ac homopolar machine for flywheel energy storage," IEEE Transactions on Energy Conversion, vol. 30, no. 4, pp. 1670-1678, Dec 2015.

[32] M. Andriollo, F. Bortot, and A. Tortella, "Disc-type pm machine for the electromagnetic conversion/suspension of a flywheel system," in 2015 International Conference on Renewable Energy Research and Applications (ICRERA), Nov 2015, pp. 739-744.

[33] C. Ye, J. Yang, F. Xiong, and Z. Q. Zhu, "Relationship between homopolar inductor machine and wound-field synchronous machine," IEEE Transactions on Industrial Electronics, 2019, doi: 10.1109/TIE.2019.2898577.

[34] M. Garcia-Gracia, M. A. Cova, M. T. Villen, and A. Uson, "Novel modular and retractable permanent magnet motor/generator for flywheel applications with reduced iron losses in stand-by mode," IET Renewable Power Generation, vol. 8, no. 5, pp. 551-557, July 2014.

[35] J. G. Bitterly and S. E. Bitterly, "Flywheel based energy storage system," U.S. Patent 5614 777, Mar. 1997.

[36] S. R. Holm, "Modeling and optimization of a permanent magnet machine in a flywheel," Ph.D. dissertation, Technische Universiteit Delft, Delft, Nov 2003.

[37] T. D. Nguyen, K. Tseng, S. Zhang, and H. T. Nguyen, "A novel axial flux permanent-magnet machine for flywheel energy storage system: Design and analysis," IEEE Transactions on Industrial Electronics, vol. 58, no. 9, pp. 3784-3794, Sep. 2011.

[38] J. eun Yi, K. W. Lee, B. Kim, J. Ko, S. Jeong, and M. D. Noh, et al., "Micro-flywheel energy storage system with axial flux machine," in 2007 IEEE/ASME international conference on advanced intelligent mechatronics, Sep. 2007, pp. 1-6.

[39] A. Cavagnino, M. Lazzari, F. Profumo, and A. Tenconi, "A comparison between the axial flux and the radial flux structures for PM synchronous motors," IEEE Transactions on Industry Applications, vol. 38, no. 6, pp. 1517-1524, Nov 2002. 